\section{BADN WELCOMES NEW PRESIDENT}

Bedfordshire dental nurse Jane Dalgarno became the 55th President of the British Association of Dental Nurses at a Presidential Inauguration ceremony held at the NEC, Birmingham.

Jane, who works as Clinical Workforce Development Manager for the Community Dental Services (CIC) in Bedford, holds a BSc (Hons) in Primary Dental Care and is currently working towards an MSc in Applied Dental Professional Practice.

Jane started her career in Dental Nursing in 1986 on a youth training programme in general dental practice in Luton, passing the National Certificate in November 1993. Since qualifying, she has completed qualifications in Oral Health Education, Sedation and Dental Radiography, gained her Certificate in Post Compulsory Education and also holds the City \& Guilds A1/A2 assessors award. She currently teaches on the Oral Health Education Certificate and Certificate in Dental Sedation Nursing courses, is an examiner for the National Examining Board for Dental
Nurses for the National Diploma and for the Certificates in Oral Health Education and Dental Sedation Nursing Awards. Jane is also Programme Director for the Foundation Degree in Advanced Dental Nursing for Health Education Kent, Sussex and Surrey.

Jane joined the Bedfordshire Community Dental Services in 1995. The service subsequently became the Personal Dental Services in 2001 and Community Dental Services, a social enterprise, in 2011.

In her inaugural speech, Jane said: I am a practising dental nurse committed to raising the professional voice of the dental nurse in the national arena and seeking appropriate support for dental nurses in the workplace.'

Jane is also a member of the Faculty of General Dental Practice (UK) and of the Society for Education and Training, and sits on the Local Dental Education Committee in Bedfordshire, as well as the NEBDN Sedation Committee. She was previously the Seconded Member for Education to BADN Council, and BADN Regional Coordinator for London and the South East.

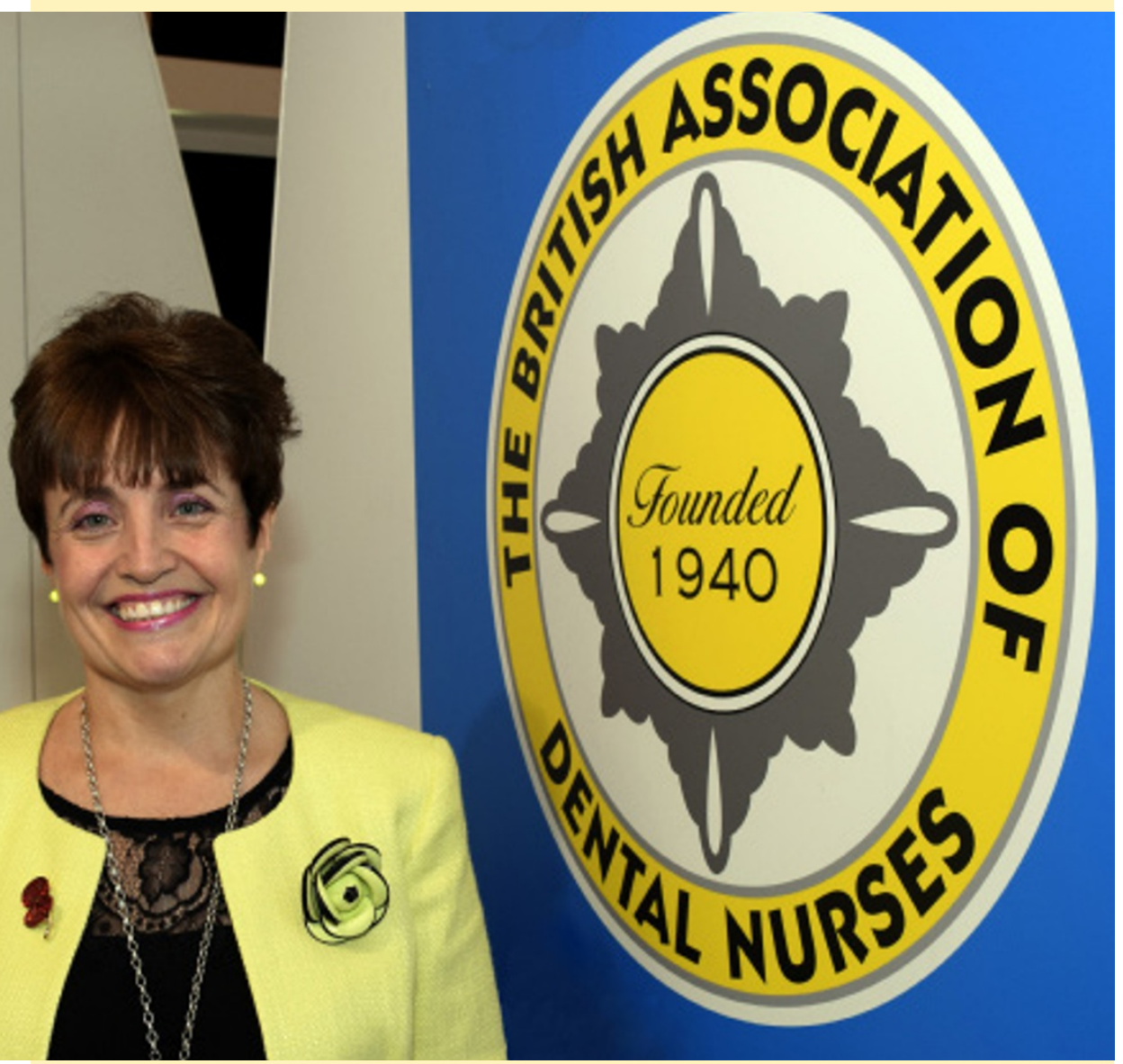

African surgeoms learn from UK head and meck specialists

A delegation of African surgeons spent four days at Birmingham's Queen Elizabeth Hospital learning from leading UK and world experts in head and neck surgery.

The two specialists visited the UK to attend the European Head and Neck Course led by British Association of Oral and Maxillofacial Surgeons (BAOMS) Maxillofacial and Head and Neck Consultant, Sat Parmar and ENT Consultant Surgeon, Paul Pracy.

The delegation included Rwandanbased doctor, Dr Magabo. The aim of Dr Magabo's visit, which was funded by BAOMS, was to gain a stronger understanding of the UK's approach to head and neck surgery in order to apply the skills and knowledge that he acquired back in his home town.

The three day course covered the current management of head and neck cancer within a multidisciplinary framework. The course aimed to present a combined approach towards the management of patients with head and neck cancer through the use of surgery, radiotherapy and chemotherapy. There was also a one day course on Chemoradiotherapy in Head and Neck cancer aimed at surgeons.

Dr Magabo, 40, who gained his qualifications in Head and Neck

Surgery at the University of Cape Town, having previously studied in Nairobi, Kenya and who now works in a hospital in Rwanda, said: 'Oral and Maxillofacial surgery is an extremely dynamic field and this course provides me with the opportunity to catch up on what is happening across it. I am really looking forward to being able to transfer the mass of knowledge I gain from the course back to my hospital in Rwanda.'

Sat Parmar, Maxillofacial Head and Neck Consultant said: 'This is a great initiative by BAOMS and ENT UK to sponsor doctors from developing countries aimed at improving treatment in their own countries.' 